\title{
Customers and Services Receivers Requirements in World Class Organizations
}

\author{
Nasser Fegh-hi Farahmand \\ Department of Industrial Management, Tabriz Branch, Islamic Azad University, Tabriz, Iran \\ E-mail: farahmand@iaut.ac.ir
}

\begin{abstract}
With the rise in the standard of living, resulting from increased factory productivity changes in the needs and demands of the population. House of Quality (HOQ) has been widely used to translate Customers \& Services Receivers (C\&SR) requirements to a Products \& Services (P\&S) technical attributes. Products \& Services have emerged as the fastest growing component of international trade.

Correctly rating the importance of every C\&SR requirement is essential to the HOQ process because it will largely affect the final target value of a P\&S technical attributes. This paper proposes a new C\&SR requirements ranking method that considers organizations information. In today's environment, there are usually several P\&S to fulfill certain functions. The success of a P\&S depends not only on whether it meets the C\&SR requirements, but also on how it compares with other organizations P\&S. Most previous methods focus only on the C\&SR perspective, and ignore the organizational environment. In according with the research methodology that was literature review, the proposed method considers social position, current performance and C\&SR viewpoint to produce the ratings.
\end{abstract}

Keywords: House of quality, customer \& service receiver requirement, organizational environment, world class organization.

\section{Introduction}

Organizations compete with the quality level of their Products \& Services. A Products \& Services organization, which cannot manage Organizations competition, will have problems surviving. In order to be able to do this successfully, the Products \& Services world class organization has to view its business and its customer relationships from a Products \& Services quality improvement perspective. There are always relationships between a Products \& Services organization and its Customers \& Services Receivers.

The key issue is whether the firm wants to make use of these relationships in the way it manages Customers \& Services Receivers or not, and whether a given Customers \& Services Receivers wants to be an actively managed relationship with the Products \& Services provider, or not.

In this paper, the importance and growth of the Products \& Services sector reviewed. The Products \& Services sectors are expanding globally. The percentage of growth of the different economic criteria in the Products \& Services sector is continuing to increase as the manufacturing base declines. Therefore, it can say that design management in the Products \& Services sector is becoming increasingly important and this importance will continue to grow over this century.

\section{World Class Organizations}

World class organizations are facing fundamental issues such as how to design and implement an effective quality service delivery system, which will help to establish and to retain global market share. Much of the published work on quality focuses on manufactured Products \& Services, but managers are paying more attention to emphasizing quality in services.

While organizations have always played a key role in the economies of all major societies, it was not until the 2000s that this role gained wide appreciation and featured on the social, managerial and political agenda. While the definition of what constitutes an organization varies, it generally based on the number of employees and P\&S turnover (Zuckerman, E. W., 2000, 228).

In practice, organizations usually characterized by simple organizational structures, which facilitate rapid decision-making and often display, a high degree of innovation.

The management techniques and operating structures employed are one way of identifying the maturity of the organization (Bridge, S. O'Neill, K \& Cormier S, 2002, 651). 
The range and sophistication of World Class Organization (WCO) techniques status is beyond the aspirations and competence of many small, medium and large sized organizations (Feghhi farahmand, 2004, 166).

The techniques covered by WCO must make recognizable and relevant to the organizations if there is to be any possibility of them being adopted (Adebanjo, D. \& Kehoe, D.2001, 325).

When the concept of WCO introduced into popular parlance, the term was seen to embrace the techniques and factors (Mason, C and Stark, M, 2004, 332). However, techniques of WCO well established before 2000 and would include Statistical Process Control (SPC) as one of the early manifestations.

The substantial increase in techniques can related in part to the growing influence of the organizations philosophies.

In recent years, it has expanded most notably to include simultaneous engineering, benchmarking and increasing emphasis on issues relating to organization strategy.

Clearly, the management of organizations seeking world class status would appear to be faced with a far more complex task than was the case previously (Feghhi farahmand, 2004, 169). One of the main reasons for the inappropriate use of advanced organizations technologies and techniques in many organizations arises from an inadequate understanding of their Production \& Operation (P\&O) problems and the integrated nature of modern technology.

All too often, technological solutions are imposed which necessitate the organization to engage in an organizational metamorphosis to effectively employ them (Bolton, B and Thompson J, 2003, 111). These can often produce sub optimal results. Ideally, the reverse process should occur, where the organization progresses from a detailed understanding of its problems, which ensures that a particular technology or technique is adapted to meet the needs of the organization (Curran, J. and Blackburn, R, 2002, 117). This process of adaptation should also take into account the P\&O, size and workforce. WCO needs to frame in terms of the needs of the organization rather than the other way round.

For many organizations, becoming world class does not always mean implementing the most advanced technologies; instead, its competitiveness may arise from the flexibility and skills of its workforce, or a unique market niche and organization strategy (Shemwell, D, 1998, 158). A useful framework for analyzing the deficiencies of the organizations operations is to identify gaps in the P\&O that lead to inefficiencies and compare these to its own model of what constitutes world class in its field.

By applying an iterative process and identifying gaps in its performance, the organization can assess the suitability of potential solutions at a level appropriate to the requirements and resources of an organization. Gradually move nearer to its model of world class (Jagdish, N, 2001,75) as shows at Fig. 1 that our organization basically requirements are suitable organizational Technology, Structure, Functions and Behaviors (TSFB), as the same of strongly bridge for set up to previous and next systems through pull system approach (Feghhi farahmand, 2004, 261; Baron, R. M. and Kenny, D. A.1986, 288).

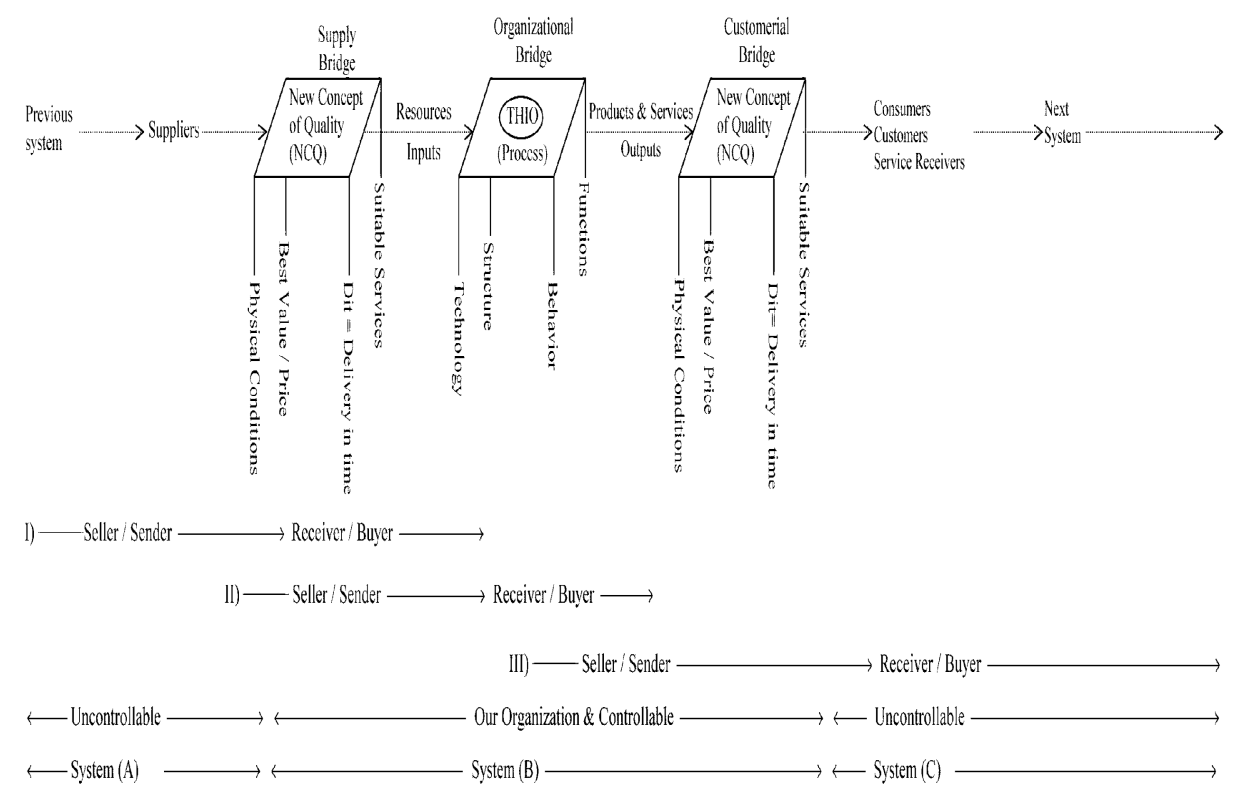

Fig. 1: Organization position and requirements 
While the concept of what constitutes WCO has received considerable attention in the academic literature, it developed principally in relation to the needs of larger scale organizations. Given that small, medium and large size organizations make up a significant proportion of the organization capacity in social economies there is a clear need for a rethink of the concept in order to make it relevant to their specific needs (Brunett, Ken, 2001, 337).

Faced with a growing list of the elements needed for WCO the management of organizations appears faced with a daunting task. Focusing on the organizational operation in an organization using the gap analysis framework has proved its utility in assisting the management of one organization to make progress towards a model of WCO that is applicable to their circumstances (Feghhi farahmand, 2004, 283).

By coupling quality with C\&SR service recovering satisfaction, a few tactical actions as follow can make the challenge simpler and provide leadership (Johnson, M.D.\& Gustafsson, A, 2000, 288):

1) Obtain support from the board of directors. An organization's total quality efforts must begin at the very top (Wiseman, R. M. and Gomez Mejia, L. R., 1998, 844). Begin with the board of directors; one method of obtaining their support is to conduct a quality survey among them. Such questions could include (Collis, D. J., 1998, 21):

a) Has an estimate been made of the cost of poor quality?

b) What measures are using to judge quality?

c) What are current performance levels?

d) How does quality of C\&SR satisfaction compare with other organizations?

2) Prepare an action plan. The answers to these and other questions will provide valuable insights into the existing corporate culture and indicate the organization's readiness for adopting quality. An action plan is on based on the survey feedback should then be formulated by the top management.

3) Vision/mission statement. Develop a vision or mission statement if the organization does not have one already (Feghhi farahmand, 2002, 125). The key to the initial adoption of quality is continuous communication of the vision within a comprehensive communication plan (Barkham, R, 1996, 221).

4) Train senior management in quality. Organization's with successful quality cultures start by training and educating senior management, followed by all employees (Feghhi farahmand, 2003, 665). The establishment of quality teams is a top priority (Adebanjo, D. Kehoe, D, 2001, 112).

5) Establish top-level quality committee. An essential ingredient for success is a senior quality committee, which provides leadership in quality and stimulates cultural change. This should be chaired by the top management and comprise the entire senior management team and the individual responsible for quality. Depending on the size and structure of the organization, these committees established within operating divisions, functional group or by geography. The responsibilities of a senior quality committee can include (Stutely, R, 2003, 172):

a) Establishing strategic quality goals (Baysinger, B. D., Kosnik, R. and Turk, T. A.1991, 122)

b) Allocating resources (Bethel, J. E. and Liebeskind, J., 1993, 374)

c) Sanctioning quality improvement teams (Cameron, K. S., 1994, 158)

d) Reviewing key indicators of quality (Capron, L., 1999, 255)

e) Estimating the cost of poor quality (Collis, D. J. and Montgomery, C. A., 1995, 741)

f) Ensuring adequate training of employees (Finkelstein, S., 1992, 55)

g) Recognizing and rewarding individual and team efforts (Gibbs, P. A., 1993, 118)

6) Conduct a C\&SR satisfaction survey. This sponsored by the top management to send a clear message throughout the organization that quality linked to customer satisfaction. The top management and senior executives should then present the results to all employees. Detailed strategies for improving customer satisfaction devised and communicated (Walsh timothy, 2002, 421).

7) Set goals for quality and C\&SR satisfaction. The results of the C\&SR satisfaction survey lead the top management and senior management to establishing a set of quality goals. Although the whole organization can provide input to this task, the setting of goals is part of management's leadership responsibility (Watts, H. D., Wood, A. M. \& Wardle. P, 2003, 522).

8) Incorporate quality performance in management reward system. As with financial performance rewards, quality improvement goals can be incorporated into executive management compensation models to help achieve the desired quality results (Vaara, E., Tienari, J., Piekkari, R., 2005, 108). For example, a bank uses a number of key quality indicator, employee satisfaction and C\&SR satisfaction goals to determine 5 percent of executive manager's bonuses (Westhead, P., 2001, 222). However, it is important not to hold senior management totally responsible until the foundations of quality (i.e. key indicators, training mission statement, goals, culture, etc.) are firmly established (Kendall st., friezes Ja. steeples Jo. et al, 2004, 558). Initially, top 
management must prove its capacity to deliver quality before it used as an assessment criterion for a reward package.

9) The quality obsesses. Top management should be obsessed with quality. Strong corporate cultures established through leadership by example and strategy. Adopt an obsession with quality (Feghhi farahmand, 2004, 405).

\section{C\&SR Requirements in House of Quality}

House of Quality is a diagram, resembling a house, used for defining the relationship between customer \& service receiver requirement desires and the P\&S capabilities. It is a part of the Quality Function Deployment (QFD) and it utilizes a planning matrix to relate what the customer \& service receiver wants to how a organizations that produces the P\&S is going to meet those wants. It looks like a House with a correlation matrix as its roof, customer \& service receiver wants versus P\&S features as the main part, competitor evaluation. It based on the belief that P\&S should designed to reflect customer \& service receiver desires, requirement and tastes. It also reported to increase cross-functional integration within organizations using it, especially between marketing, engineering and manufacturing.

The basic structure is a table with "Whats" as the labels on the left and "Hows" across the top. The roof is a diagonal matrix of "Hows vs. Hows" and the body of the house is a matrix of "Whats vs. Hows". Both of these matrices filled with indicators of whether the interaction of the specific item is a strong positive, a strong negative, or somewhere in between. Additional annexes on the right side and bottom hold the "Whys" as market research, etc. and the "How Muches". Rankings based on the Whys and the correlations can used to calculate priorities for the Hows.

House of Quality analysis can also be cascaded, with "Hows" from one level becoming the "Whats" of a lower level; as these progresses the decisions get closer to the engineering/manufacturing details.

\section{C\&SR Requirements in World class organizations}

World class organizations identified the customer \& service receiver requirement that have special requirements or restrictions. Because they established good working relationships with relative systems and many of the customer \& service receivers, organizations can often limit the costs and risks by having suitable systems for doing of customer \& service receiver requirement.

World class organizations have a list of customer \& service receiver requirement and it have special requirements and additional requirements.

It's important to work with departments of world class organizations as well as organizational customer \& service receivers to allow $\mathrm{P} \& S$ to monitor and check the quality of them. World class organizations goal is to make sure P\&S by monitoring systems.

\section{C\&SR Requirements in World Class Organizations Methods}

In the current literature, some existing methods incorporate organization information to prioritize C\&SR requirements that they are as follows:

1) Quality House Method: House of Quality Method (HOQM) has been widely used as a multi functional design tool to translate C\&SR requirements to a P\&S technical attributes. $\mathrm{HOQ}$ originated in the late 1960 s and early 1970s in Japan (Akao, 1990, 251). The primary functions of Quality Function Deployment (QFD) are P\&S development, quality management, and C\&SR needs analysis (Xie, Tan, Goh, 2003,14).

Thus, HOQ used to help design teams to develop P\&S with higher quality to meet or surpass C\&SR requirements. With the development and widespread use of $\mathrm{HOQ}$, its application areas expanded to much wider fields including design, planning, decision making, engineering, management, teamwork, timing, satisfaction, costing and so on (Chan \& Wu, 2002, 178).

The inherent incentive of the widespread use of $\mathrm{HOQ}$ is its benefits to practitioners. Many papers (Sullivan, 1986, 27; Hauser and Clausing, 1988, 85; Zairi \& Youssef, 1995: 92; Chan \& Wu, 2005, 118) have mentioned the benefits of $\mathrm{HOQ}$. Correctly rating the importance of every C\&SR requirement is essential to the $\mathrm{HOQ}$ process because it will largely affect the final target value of a P\&S technical attributes. Traditionally, capturing C\&SR requirements involves three steps in $\mathrm{HOQ}$ :

a) Identifying C\&SR requirements (Haynes et al 2002, 664)

b) Structuring C\&SR requirements (Hitt et al 2006, 994)

c) Determine of the importance weight for the individual C\&SR requirements. 
The first two steps usually accomplished via society survey combined with expert opinion. Many papers have proposed several mature methods on this topic. This paper, will focus on the third step, to rate the C\&SR requirements' importance because, today the success of a P\&S in a society place depends not only on how well it meets the C\&SR requirements, but also how it compares with other organizations P\&S (Chan \& Wu, 2002, 85).

Therefore, it is important to integrate organization analysis into P\&S design and development. Then, the ranking of C\&SR requirements for the allocation of development resources should based also on organization analysis.

This paper introduces C\&SR requirements rating method that takes organizations into consideration and rates C\&SR requirements from perspectives as competition, performance, and C\&SR and so gives more priority to those requirements that lag behind organizations, have a lower C\&SR satisfaction that C\&SR think more important. The weights indicate the most important C\&SR requirements that organizations should focus on (Belsey et al., 1980, 854).

2) Point Scoring Method: Many papers published in this field of Point Scoring Method (PSM), and several rating methods have been proposed. The earliest method is to use a Point Scoring Scale (PSS), such as 1, 3, 5, and so on. Precise scoring methods such as 1-10 also are used (Griffin, Hauser, 1993, 336). The score often obtained from C\&SR survey or expert opinion. However, different C\&SR or experts have different attitudes toward the same requirement. To cope with this situation, use a group decision-making technique to obtain the importance weights for C\&SR requirements is proposed (Lai et al., 1998, 299; Ho et al., 1999, 624). However, this method cannot always work effectively because many C\&SR tend to rate every requirement to the highest importance.

3) Analytic Hierarchy Process Method: Analytic Hierarchy Process Method (AHPM) proposed to be used in rating C\&SR requirements and the sensitivity (Akao, 1990, 341; Armacost et al., 1994, 187; Aswad, 1989, 95; Karsak et al., 2002, 75) of the C\&SR voice in HOQ analyzed (Xie, Goh, and Wang, 1998, 289). However, C\&SR opinions are often vague and contain ambiguity and multiple meanings (Fung et al., 1998, 322; Khoo \& Ho, 1996, 95). FT is used in AHP (Kwong \& Bai, 2002, 662; Vanegas \& Labib, 2001, 254) and other methods are also proposed to use a conjoint analysis method (Gustafsson \& Gustafsson, 1994, 119) to determine the relative importance of the C\&SR requirements. From the C\&SR perspective, all methods have the same characteristics that coordinated with the basic spirit of HOQ, C\&SR driven design. However, in today's, several P\&S can satisfy the C\&SR that simply meeting C\&SR requirements cannot guarantee a successful P\&S. Organizations must consider their positions to make sure that their own P\&S would not lag behind other organizations P\&S.

4) Present Point Method: Present Point Method (PPM) is contains information characterizing the ability to present the P\&S or service, based on how well each C\&SR need is met (Cohen, 1995, 390). Usually a Present Point (PP) indicates a unique present position to separate one's own P\&S from organizations. The organization can be proud of this present position because organizations may not perform well in this C\&SR requirement. PP can found among the areas that organizations perform poorly or a bottleneck in the technology or a technological breakthrough and can categorized into three types: Strong, Moderate, and Poor, indicating the organization opportunity from most to least, respectively. Every C\&SR requirement can categorized into the three categories. Based on this categorization, a coefficient can assigned to each type of PPM. The most commonly used values are 1, 1.25, and 1.5, corresponding poor PP, moderate PP, and strong PP, respectively. The final importance weight computed as Formula (1):

$$
\text { Final importance weight }=\text { relative importance rating } \times \text { PP value }
$$

The relative importance rating obtained from the traditional rating methods, such as C\&SR survey, expert opinion, AHP, and so on. The PPM is very straightforward, and there are many papers discussing it in $\mathrm{HOQ}$ (Cohen, 1995, 112; Robertshaw, 1995, 331). However, this method is very subjective and may cause some problems. PPM cannot help designers to find the C\&SR requirement that can be a strong point. It can only help to highlight the C\&SR requirement that designers have decided to be a strong point.

5) Information Feedback Method: The use of the Information Feedback Method (IFM) in P\&S planning is a concept in information theory (Chan et al., 1999, 33). It measures the expected information content of a certain message and becomes an important concept in social science. This method analyses the C\&SR assessment of organization performance and its organizational information, to generate the organization priority ratings. It gives the highest value to the C\&SR requirement in which all the organizations perform the same. It assumes that when all organizations perform the same, it means there is a good opportunity to be outstanding. In fact, these assumptions may not be correct in many situations. For example, an organization performs badly in one C\&SR requirement, and according to the IFM, this requirement is not important. However, the organization cannot simply overlook its disadvantage. It may be a good opportunity for organizations to attack one's own P\&S.

6) Rating Method: Rating Method (RM) is a new method that can used to obtain the importance weight of C\&SR requirements systematically (Xie et al., 2003, 28). It also analyses the organization performance information to 
generate the weights (Greene, W. H., 2000, 220). The difference is that the proposed method does not simply overlook own P\&S disadvantages. Instead, it can help organizations find out where the improvement should make mostly. This method is to help design teams find the most important C\&SR requirements for their own organization. In this way, they can set these C\&SR requirements at a prior position and devote time and effort to improve to get the organization advantage.

\section{Results}

The organizational challenges generally include limitations or lead-time on scheduling appointments of Products \& Services (P\&S), inability to observe the unloading process, handling requirements and charges and excessive penalties for minimally late deliveries.

Organization must carefully monitor the P\&S and make sure it protected during delivery. In addition, the fact organization making multiple stops often with unloading delays adds additional complexities to insure that the P\&S stay compliant with service.

Organizational procedures in place to anticipate and manage the challenges faced at receivers of P\&S. It must organize in a quality management system that is world class organization certified. This quality management system designed to organizations on four key objectives including on time, intact, attractive and no surprises.

Some of the challenges that need to anticipate include:

a) Limited hours for P\&S making appointments;

b) Specific days for $\mathrm{P} \& S$ receiving certain type of freight;

c) Receiving of P\&S at any time;

d) Fees for P\&S;

Anyhow, world class organizations developed an extensive database on thousands of P\&S receivers throughout the world. World class organizations are familiar with their P\&S requirements and anticipate typical issues or problems to insure P\&S deliveries with develop of good working relationships with these receivers to help expedite getting in and out of their locations as much as possible. Wherever possible, it want to use systems to unload and do the handling, including sorting and segregating. This insures that the product is well cared for receivers. In addition, it reduces and manages handling costs for most shippers with their receivers.

\section{Conclusions}

Organizations compete with the quality level of their Products \& Services. A Products \& Services organization, which cannot manage Organizations competition, will have problems surviving.

In order to be able to do this successfully, the Products \& Services world class organization has to view its business and its customer relationships from a Products \& Services quality improvement perspective. There are always relationships between a Products \& Services organization and its Customers \& Services Receivers.

The key issue is whether the firm wants to make use of these relationships in the way it manages Customers \& Services Receivers or not, and whether a given Customers \& Services Receivers wants to be an actively managed relationship with the Products \& Services provider, or not.

In this paper, the importance and growth of the Products \& Services sector reviewed. The Products \& Services sectors are expanding globally. The percentage of growth of the different economic criteria in the Products \& Services sector is continuing to increase as the manufacturing base declines. Therefore, it can said that design management in the Products \& Services sector is becoming increasingly important and this importance will continue to grow over this century.

World class organizations are facing fundamental issues such as how to design and implement an effective quality service delivery system, which will help to establish and to retain global market share. Much of the published work on quality focuses on manufactured Products \& Services, but managers are paying more attention to emphasizing quality in services.

One reason is the general perception that Products \& Services quality is not good. Therefore improving quality is becoming a major objective in world class organizations throughout the world. The recognition that survival much less growth in the Products \& Services sector is a function of quality led to the increasing emphasis on quality.

World class organizations have witnessed what has happened to manufacturers that allowed the quality of their Products \& Services to deteriorate. They also recognize that providing high-quality Products \& Services to keep a customer is much less expensive than acquiring a new one. Products \& Services quality has a major effect on the ability to attract and retain both Customers \& Services Receivers and employees, and it contributes directly to superior productivity. In according with the research methodology that was literature review, the proposed method considers social position, current performance and C\&SR viewpoint to produce the ratings. 


\section{References}

A. Kaufmann and M.M. Gupta (1985)., Introduction to fuzzy arithmetic: Theory and application, Van Nostrand Reinhold, New York.

Adebanjo, D. Kehoe, D. (2001), Teamwork and Customer Focus, Managing Quality, Vol.12, no.10

Akao, Y. (1990), Quality function deployment, Productivity Press, Cambridge, MA.

Akao, Y. Akao, (1990), Quality function deployment: integrating customer requirements into product design, Productivity Press, Cambridge.

Ansoff, H. I. (1965). Corporate Strategy: An analytic approach to business policy for growth and expansion. New York: McGraw-Hill.

Anton, J. Perkins, D. Feinberg, R.A. (1998), Voice of the Customer, Bard Press.

Arash Shahin (2009), Growth of the service sector: a demand for the use of quality improvement techniques to increase service quality, The Third International Conference on Quality Management, University of Newcastle

Armacost et al. (1994), An AHP framework for prioritizing customer requirements, IIE Transactions. no 16.

Armacost, P.J. Componation, M.A. Mullens and W.W. Swart (1994), An AHP framework for prioritizing customer requirements in QFD: an industrialized housing application, IIE Transactions 26 (4), pp. 72-79.

Aswad, A. (1989), Quality function deployment, IIE integrated systems conference, Norcross, GA.

Aswad, A. (1989). Quality function deployment: a systems approach. In Proceedings of the 1989 IIE integrated systems conference (pp. 27-32). Norcross, GA.

Barkham, R, (1996), The Determinants of small Organization Growth, London, Jessica Kingsley.

Baron, R. M. and Kenny, D. A. (1986), The distinction in social research, Journal of Personality and Social Psychology, 51.

Baysinger, B. D., Kosnik, R. and Turk, T. A. (1991), Effects ownership structure, Academy of Management Journal, 34.

Belsey, D. A., Kuh, A. and Welsch, M. E. (1980), Regression Diagnostics, New York: John Wiley.

Bethel, J. E. and Liebeskind, J. (1993). The effects of corporate ownership on corporate, Strategic Management Journal, 14.

Bolton, B and Thompson J. (2003), Entrepreneurs and Technique, London: Butterworth Heinemann.

Bridge, S. O'Neill, K and Cormier S. (2002), Understanding Enterprise, London: Macmillan Business.

Brunett , Ken , (2001), The Handbook of Key Customer Relationship Management, prentice Hall

C. Temponi, J. Yen and W.A. Tlao (1999), House of quality: a fuzzy logic-based requirements analysis, European Journal of Operational Research 117 (2), pp. 340-354.

C.K. Kwong and H. Bai (2002), A fuzzy AHP approach to the determination of importance weights of customer requirements in quality function deployment, Journal of Intelligent Manufacturing 13 (5), pp. 367-377.

Cameron Kim S, (1996), A study of organizational effectiveness and its predictors, Management science review.

Cameron, K. S. (1994). Strategies for successful organizational downsizing, Human Resource Management, 33.

Capron, L. (1999), The long term performance of horizontal learning, Strategic Management Journal, 20.

Chan and Wu, (2002), Quality function deployment, European Journal of Operational Research, no 153.

Chan and $\mathrm{Wu},(2005)$. A systematic approach to quality function deployment, Omega 33.

Chan et al., (1999), Customer needs in quality function deployment by fuzzy, Journal of Production, no 37.

Chandler Alfred Jr, (1992), Strategy and structure, Cambridge mass, M.I.T press.

Chen and Weng, (2006), Engineering designs in HOQ, European Journal of Operational Research, no 172.

Cohen, L. (1999), Quality function deployment, Addison Wesley, Massachusetts.

Colin Carnal Susan (1988), Management principles policy, ICSA Cambridge.

Collis, D. J. (1998), Creating competitive advantage, Harvard Business Review, 76.

Collis, D. J. and Montgomery, C. A. (1995), Competing on resources, Harvard Business Review, July-August, 73.

Curran, J. and Blackburn, R. (2002), Business planning and Local Economic Networks, London: Paul Chapman.

D.G. Ullmand (1992), The mechanical design process, McGraw-Hill, New York.

Denison Daniel R, (1995), Corporate culture and organizational effectiveness, New York, John wiles \&sons.

E.E. Karsak (2004), Fuzzy multiple objective programming framework to prioritize design requirements in quality function deployment, Computers \& Industrial Engineering 47, pp. 149-163.

E.E. Karsak, S. Sozer and S.E. Alptekin (2002), Product planning in quality function deployment using a combined analytic network process and goal programming approach, Computers \& Industrial Engineering 44 (1), pp. 171-190.

E.S. Ho, Y.J. Lai and S.I. Chang (1999), An integrated group decision-making approach to quality function deployment, IIE Transactions 31, pp. 553-567.

Evans and Lindsay, (2002), Management and control of quality, Singapore, Thomson Learning.

Feghhi Farahmand, Nasser (2001), Executive Management Process, Islamic Azad University, Tabriz Branch, Iran, pp 99-113.

Feghhi Farahmand, Nasser (2003), Permanent Management of Organization, First edition, Frouzesh Publication, Tabriz, Iran, pp 70-83. 
Feghhi Farahmand, Nasser (2003), Strategic Structure of Organization Management Process, Forth edition, Islamic Azad University, Tabriz Branch, Iran, pp 41-125.

Feghhi Farahmand, Nasser (2005), Strategic Management of Organization, First edition, Frouzesh Publication, Tabriz, Iran, pp 85-149.

Feghhi Farahmand, Nasser (2009), Organization Strategic Plan compilation, First edition, Frouzesh Publication, Tabriz, Iran, pp 74-314.

Feghhi farahmand, Nasser (2011), Active and Dynamic Management of Organization, Second edition, Frouzesh Publication, Tabriz, Iran, pp 87-90.

Feghhi Farahmand, Nasser (2011a), Technology Management of Organization, Second edition, Frouzesh Publication, Tabriz, Iran, pp 11-18.

Finkelstein, S. (1992), Power in top management teams, measurement and validation, Academy of Management Journal, 35.

Fung et al., (1998), Customer requirement analysis, International Journal of Production, no 38.

Fung et al., (2006), Quality function deployment under uncertainties, Fuzzy Systems, no 157.

Gibbs, P. A. (1993), Determinants of corporate restructuring, Strategic Management Journal, 14.

Greene, W. H. (2000), Econometric Analysis, Cliffs, NJ: Prentice Hall.

Griffin and Hauser, (1993), The voice of the customer, Marketing Science, no 12.

Gustafson, A.,(1994), Exceeding customer expectations, Quality function deployment, Novi, MI.

Gustafsson, A., \& Gustafsson, N. (1994). Exceeding customer expectations. In Proceedings of the sixth symposium on quality function deployment (pp. 52-57). Novi, Ml.

Haunschild, P. R. (1994), How much is that organization worth? Administrative Science Quarterly, 39.

Hauser and Clausing, (1988), The house of quality, Harvard Business Review.

Hauser and Clausing, (1996), The house of quality, Management Review. no 24.

Hauser and Clausing, 1996 J.R. Hauser and D. Clausing, The house of quality, IEEE Engineering Management Review 24 (1) (1996), pp. 24-32.

Hayes R. and Clark K, (2003), Why some factories are more productive than others, Harvard Business Review.

Haynes, M., Thompson, S. and Wright, M. (2002), Organization performance, The Journal of Industrial Economics, 1.

Hitt, M. A., Bierman, L., Uhlenbruck, K. and Shimizu, K. (2006), Resources, Academy of Management Journal, 49.

Ho et al., (1999), An integrated group decision making approach to QFD, IIE Transactions, no 31.

http://en.wikipedia.org/wiki/House_of_Quality

http://www.trademarktrans.com/managing-receiver-requirements

J. Wang (1999), Fuzzy outranking approach to prioritize design requirements in quality function deployment, International Journal of Production Research 37 (4), pp. 899-916.

J.R. Evans and W.M. Lindsay (2002), Management and control of quality (5th ed.), Thomson Learning, Singapore.

J.R. Hauser and D. Clausing (1988), The house of quality, Harvard Business Review, pp. 63-73.

Jagdish, N. (2001), Customer Relationship Management: Concept, Tools, Applications, McGraw Hill.

Johnson, M.D. Gustafsson, A. (2000), Improving customer satisfaction, Jossey Bass Press.

Karsak et al., (2002), Product planning in quality function deployment, Industrial Engineering, no 44.

Karsak, E., (2004), Fuzzy multiple objective programming in qfd, Industrial Engineering, no 47.

Kaufmann and Gupta, (1985), Introduction to fuzzy arithmetic Van No strand Reinhold, New York.

Kendall st., friezes Ja., steeples Jo, etal.(2004), Flexibility program, Journal of clinical engineering.

Khoo and Ho, L.P., (1996), Framework of a fuzzy QFD system, International Journal of Production Research, no 34.

Kwong and Bai, C.K., (2002), A fuzzy AHP approach in QFD, Journal of Manufacturing, no 13.

L. Cohen (1995), Quality function deployment: How to make QFD work for you, Addison-Wesley, Massachusetts.

L.H. Chen and M.C. Weng (2006), An evaluation approach to engineering design in QFD processes using fuzzy goal programming models, European Journal of Operational Research 172 (1), pp. 230-248.

L.K. Chan and M.L. Wu (2002), Quality function deployment: A literature review, European Journal of Operational Research 143, pp. 463-497.

L.K. Chan and M.L. Wu (2005), A systematic approach to quality function deployment with a full illustrative example, Omega 33 (2), pp. 119-139.

L.K. Chan, H.P. Kao, A. Ng and M.L. Wu (1999), Rating the importance of customer needs in quality function deployment by fuzzy and entropy methods, International Journal of Production Research 37 (11), pp. 24992518.

L.P. Khoo and N.C. Ho (1996), Framework of a fuzzy quality function deployment system, International Journal of Production Research 34 (2), pp. 299-311.

L.P. Sullivan (1986), Quality function deployment, Quality Progress 19, pp. 39-50.

L.V. Vanegas and A.W. Labib (2001), A fuzzy quality function deployment (FQFD) model for driving optimum targets, International Journal of Production research 39 (1), pp. 99-120.

Lai et al., Y.J. Lai, E.S. Ho and S.I. Chang, (1998), Identifying customer preferences, Wiley, NY. 
M. Xie, K.C. Tan and T.N. Goh (2003)., Advanced QFD applications, ASQ Quality Press, Milwaukee, Wisconsin.

M. Xie, T.N. Goh and H. Wang (1998),, A study of the sensitivity of customer voice in QFD analysis, International Journal of Industrial Engineering 5 (4), pp. 301-307.

M. Zairi and M.A. Youssef (1995), Quality function deployment: a main pillar for successful total quality management and product development, International Journal of Quality \& Reliability Management 12 (6), pp. 9-23.

M. Zhou (1998), Fuzzy logic and optimization models for implementing QFD, Computers \& Industrial Engineering $35(1-2)$, pp. 237-240.

Mason, C and Stark, M. (2004), What do Investors look for in a Business Plan, International Business Journal, no32.

McKinley, W., Zhao, J. and Rust, K. G. (2000), A socio cognitive interpretation, Academy of Management Review, 25.

Morgan R, (1994), The Emergence of new organizational forms, London, no 27.

Morrow, J. L., Sirmon, D. G., Hitt, M. A. and Holcomb, T. R. (2005), Creating Value, Society Conference, Orlando.

Nixon, R. D., Hitt, M. A., Lee, H. and Jeong, E. (2004), Market reactions, Strategic Management Journal, no 25.

R.H. Zhao and R. Govind (1991), Defuzzification of fuzzy intervals, Fuzzy Sets and Systems 43, pp. 45-55.

R.Y.K. Fung, K. Popplewell and J. Xie (1998), An intelligent hybrid system for customer requirement analysis and product attribute targets determination, International Journal of Production Research 36 (1), pp. 13-34.

R.Y.K. Fung, Y.Z. Chen and J.F. Tang (2006), Estimating the functional relationships for quality function deployment under uncertainties, Fuzzy Sets and Systems 157 (1), pp. 98-120.

Robert Shaw, W. (1995), Using an objective sales point measure, Transactions from the Symposium on HOQ.

Robertshaw, W. (1995). Using an objective sales point measure to incorporate elements of the Kano model into QFD. Transactions from the 7th Symposium on QFD (pp. 201-216).

Rue, L. and Ibrahim, N. (1998), Planning and Performance, Journal of small Business Management, no 36.

Runkler, T.A. Runkler, (1997), Selection of appropriate defuzzification methods, IEEE Fuzzy Systems, no 5.

Schwenk, C. R. and Shrader, C. B. (1993), Effects of formal Strategic Planning: Theory and Practice, no 17.

Seth, A., Song, K. P. and Pettit, R. R. (2002), Value creation and destruction, Strategic Management Journal, no 23.

Shemwell, D, (1998), Practices for Sales Culture, International Journal of Marketing, Vol.16, no.7.

Shen, X.X. Tan and M. Xie, (2001), QFD on linguistic data, Journal of Manufacturing, no12.

Solvency Gavial, (1992), Handbook of industrial Engineering, John wily \&sons Inc.

Stutely, R, (2003), The definitive Business Plan, London: Financial Times Prentice Hall.

Sullivan, L.P. (1999), QFD, Quality Progress.

T.A. Runkler (1997), Selection of appropriate defuzzification methods using application specific properties, IEEE Transactions on Fuzzy Systems 5 (1), pp. 72-79.

Tempon et al., (1999), House of quality, European Journal of Operational Research, no 117

Thompson, J.D., (2004), Organizations in action, New York, Mc Graw Hill.

Ullmand, D.G., (1992), The mechanical design process, New York, McGraw Hill.

Vaara, E., Tienari, J., Piekkari, R. (2005), Circuits of power in corporation,. Journal of Management Studies, no 42.

Vanegas and Labib, (2001), A fuzzy QFD model, International, Journal of Production, no 39.

Walsh timothy.(2002), Total quality management, Equipment proceeding of National Forum.

Wang, J. (1999), Fuzzy approach to design requirements in QFD, International Journal of Production, no 37.

Watts, H. D., Wood, A. M. and Wardle. P. (2003), Making Friends or Making Things? Urban Studies.

Westhead, P (2001), Management and BP Performance, International Business Journal.no 14.

Wiseman, R. M. and Gomez Mejia, L. R. (1998), A model of managerial risk taking,. Academy of Management Review, no 23.

Woods, A. and Joyce, P. (2003), Practice of Strategic Management, International small Business Journal, no 21. WWW. QFD \& The expanded House of quality.

X.X. Shen, K.C. Tan and M. Xie (2001), The implementation of quality function deployment based on linguistic data, Journal of Intelligent Manufacturing 12 (1), pp. 65-75.

Xie, K.C. Tan and T.N. Goh, (2003), Advanced HOQ applications, ASQ Quality Press, Milwaukee, Wisconsin

Xie, T.N. Goh and H. Wang, (1998), Customer voice in QFD, International Journal of Industrial Engineering, no 5.

Y.J. Lai, E.S. Ho and S.I. Chang (1998), Identifying customer preferences in quality function deployment using group decision-making techniques. In: U. Usher, U. Roy and H. Parsaei, Editors, Integrated product and process development - Methods, tools, and technologies, Wiley, NY, pp. 1-28.

Zairi and Youssef, (1995), QFD, International Journal of Quality Management, no 22.

Zhao and Govind, R.H., (1991), Defuzzification of fuzzy intervals, Fuzzy Systems no 63.

Zhou, M. Zhou, (1998), Models for implementing HOQ, Industrial Engineering, no 35.

Zuckerman, E. W. (2000), Focusing the corporate product, Administrative Science Quarterly, no 45. 